PERcursos Linguísticos • Vitória (ES) •v. 10 •n. 26 • 2020 ISSN: 2236-2592 •

Dossiê: Linguagem, Comunicação e Cognição •

\title{
POLÍTICA EDITORIAL
}

A Revista PERcursos Linguísticos publica minimamente 3 (três) números anualmente e tem como objetivo a publicação de textos científicos nas diversas áreas da Linguística e Linguística Aplicada. Com esse propósito, abre um espaço para a um diálogo acadêmico, que possibilita o debate em torno de diferentes orientações teóricas, transitando desde os paradigmas relacionados com a descrição e a análise linguística até às instigantes perspectivas do discurso e da análise textual, e às questões típicas da ampla área de linguística aplicada.

Por definição da política editorial da Revista, são aceitas contribuições de artigos redigidos em português de pesquisadores doutores, mestres e estudantes de pósgraduação do Brasil e do exterior, bem como estudantes de graduação, preferencialmente em conjunto com seus respectivos orientadores.

Os textos submetidos para publicação na revista são avaliados anonimamente por dois pareceristas do Conselho Editorial. Caso o artigo não seja da área de avaliação desses pareceristas, consultores ad hoc emitirão o parecer também no sistema de avaliação duplo cego. No caso de discrepâncias na avaliação do artigo, ele será avaliado por um terceiro parecerista. Depois da análise, cópias dos pareceres serão encaminhadas aos autores, juntamente com instruções para modificações, quando for o caso. Os trabalhos que não responderem no devido tempo hábil para resposta, não serão publicados na edição a qual foi inserido. Dados e conceitos emitidos nos trabalhos, bem como a exatidão das referências bibliográficas, são de inteira responsabilidade dos autores. Só será admitido um artigo por chamada por autor(es).

Os artigos podem ser escritos em português, inglês ou espanhol.

Os dados e conceitos contidos nos artigos, bem como a exatidão das referências, serão de inteira responsabilidade do(s) autor(es).

Os originais apresentados não devem ter sido submetidos a outro periódico simultaneamente.

Não serão aceitos artigos de autoria de mais de três autores sem a devida justificativa que deverá ser aceita pelo conselho editorial da PERcursos. 
PERcursos Linguísticos • Vitória (ES) •v. 10 •n. 26 • 2020 ISSN: 2236-2592 •

Dossiê: Linguagem, Comunicação e Cognição•

Os direitos autorais referentes aos artigos aprovados serão concedidos, sem ônus, automaticamente à revista PERcursos Linguísticos, a qual poderá então publicá-los com base nos incisos VI e I do artigo $5^{\circ}$ da Lei 9610/98.

Os autores devem providenciar autorização para uso das imagens. Caso contrário, será necessário retirá-las e apenas descrevê-las.

Os direitos autorais referentes aos trabalhos aprovados serão concedidos, sem ônus, automaticamente à revista PERcursos Linguísticos, a qual poderá então publicá-los com base nos incisos VI e I do artigo $5^{\circ}$ da Lei 9610/98. O trabalho publicado poderá ser acessado pela rede mundial de computadores, sendo permitidas, gratuitamente, a consulta e a reprodução de exemplar do trabalho para uso próprio de quem o consulta. Essa autorização de publicação não tem limitação de tempo, ficando o site da revista responsável pela manutenção da identificação do autor do artigo. Casos de plágio ou quaisquer ilegalidades nos textos apresentados são de inteira responsabilidade de seus autores.

\section{NORMAS PARA PUBLICAÇÃO}

O trabalho deve ser digitado em Word for Windows, versão 6.0 ou superior, em papel A4 $(21 \mathrm{~cm} \mathrm{X} \mathrm{29,7} \mathrm{cm),} \mathrm{com} \mathrm{margens} \mathrm{superior} \mathrm{e} \mathrm{esquerda} \mathrm{de} 3 \mathrm{~cm}$ e direita e inferior de $2 \mathrm{~cm}$, sem numeração de páginas. A fonte deverá ser Times New Roman, tamanho 12, em espaçamento 1,5 entre linhas e parágrafos, com alinhamento justificado. Entre texto e exemplo, citações, tabelas, ilustrações, etc., utilizar espaço duplo.

Os trabalhos devem ter extensão mínima de 10 e máxima de 20 páginas, incluindo todos os dados, como tabelas, ilustrações e referências.

O trabalho deve obedecer à seguinte estrutura:

- Título: centralizado, em maiúsculas com negrito, na fonte 14 , no alto da primeira página.

- Nome do(s) autor(es): por extenso, com letras maiúsculas somente para as iniciais, em fonte 12, duas linhas abaixo do título, alinhado à direita, com um asterisco que remeterá ao pé da página para identificação da instituição a que pertence(m) o(s) autor(es). 
- Filiação institucional: em nota de rodapé, puxada do sobrenome do autor, na qual constem o departamento, a faculdade (ou o instituto, ou o centro), a sigla da universidade, a cidade, o estado, o país e o endereço eletrônico do(s) autor(es).

- Resumo: em português e inglês (abstract) para os textos escritos em português; na língua do artigo e em português para artigos escritos em língua estrangeira. Precedido desse subtítulo e de dois-pontos, em parágrafo único, de no máximo 200 palavras, justificado, sem adentramento, em espaçamento simples, duas linhas abaixo do nome do autor.

- Palavras-chave e keywords: no mínimo três e no máximo cinco; precedidas desse subtítulo e de dois-pontos, com iniciais maiúsculas, separadas por ponto, fonte normal, em alinhamento justificado, espaçamento simples, sem adentramento, com um espaço simples após o resumo.

- Texto do artigo: iniciado duas linhas abaixo das palavras-chave e keywords, em espaçamento 1,5 cm. Os parágrafos deverão ser justificados, com adentramento de 1,25 $\mathrm{cm}$ na primeira linha. Os subtítulos correspondentes às seções do trabalho deverão figurar à esquerda, em negrito, sem numeração e sem adentramento, com a inicial da primeira palavra em maiúscula. Os subtítulos obrigatoriamente utilizados (Resumo, Palavraschave, Abstract, Keywords, Referências) também se submetem a essa formatação. Deverá haver espaço duplo de uma linha entre o último parágrafo da seção anterior e o subtítulo. Todo destaque realizado no corpo do texto será feito em itálico. Exemplos aos quais se faça remissão ao longo do texto deverão ser destacados dos parágrafos que os anunciam e/ou comentam e numerados, sequencialmente, com algarismos arábicos entre parênteses, com adentramento de parágrafo.

- Referências: precedidas desse subtítulo, alinhadas à esquerda, justificadas, sem adentramento, em ordem alfabética de sobrenomes e, no caso de um mesmo autor, na sequência cronológica de publicação dos trabalhos citados, duas linhas após o texto. Para referências em geral (de livro, de autor-entidade, de dicionário, de capítulo de livro organizado, de artigo de revista, de tese/dissertação, de artigo/notícia em jornal, de trabalhos em eventos, de anais de evento, de verbete, de página pessoal), seguir a NBR 6023 da ABNT. Os documentos eletrônicos seguem as mesmas especificações requeridas para cada gênero de texto, dispostos em conformidade com as normas NBR 6023 da 
PERcursos Linguísticos • Vitória (ES) •v. 10 •n. 26 • 2020 ISSN: 2236-2592 •

Dossiê: Linguagem, Comunicação e Cognição •

ABNT; no entanto, essas referências devem ser acrescidas, quando for o caso, da indicação dos endereços completos das páginas virtuais consultadas e da data de acesso a arquivos on-line.

Para citações, seguir NBR 10520 da ABNT. Ressalte-se que as referências no texto devem ser indexadas pelo sistema autor-data da ANBT: (SILVA, 2005, p. 36-37). Quando o sobrenome vier fora dos parênteses, deve-se utilizar apenas a primeira letra em maiúscula.

No caso de haver transcrição fonética e uso de fontes do IPA, é necessário usar somente um tipo de fonte: silDoulosIPA, tamanho 12. A fonte pode ser obtida gratuitamente por meio do site: <http://scripts.sil.org/DoulosSIL_download>.

- Anexos, caso existam, devem ser colocados após as referências, precedidos da palavra Anexo, em negrito, sem adentramento e sem numeração. Os trabalhos que não se enquadrarem nas normas aqui expostas serão recusados.

O trabalho (um e somente um por grupo ou por autor) deverá ser submetido pelo site, após cadastro, em dois arquivos digitais, em formato Word for Windows (versão 6.0 ou superior), conforme as normas aqui divulgadas. No texto do primeiro arquivo, em uma folha que anteceda o artigo, devem constar os seguintes dados: nome e endereço completo do(s) autor(es), com telefone, fax e e-mail; formação acadêmica; instituição em que trabalha; especificação da área em que se insere o artigo. No texto do segundo arquivo, deverá ser omitida qualquer identificação de seu(s) autor(es), constando apenas o texto do artigo propriamente.

Serão devolvidos aos autores trabalhos que não obedecerem tanto às normas aqui estipuladas quanto às normas de formatação.

\section{Declaração de Direito Autoral}

O autor de submissão à Revista PERcursos Linguísticos cede os direitos autorais à editora da revista (Programa de Pós-Graduação em Linguística - UFES), caso a submissão seja aceita para publicação. A responsabilidade do conteúdo dos artigos é exclusiva dos autores. É proibida a submissão integral ou parcial do texto já publicado na revista a qualquer outro periódico. 
PERcursos Linguísticos • Vitória (ES) •v. 10 •n. 26 • 2020 ISSN: 2236-2592 •

Dossiê: Linguagem, Comunicação e Cognição •

Os trabalhos aqui apresentados utilizam a licença Creative Commons CC BY: Attribution- NonCommercial- NoDerivatives 4.0 International. Para mais informações, verificar:

https://creativecommons.org/licenses/by-nc-nd/4.0/

PERcursos Linguísticos

Equipe editorial

A/C Patrick Rezende (editor-gerente)

Guilherme Brambila

Elaine Cristina Borges Souza

Mônica Lopes Smiderle de Oliveira

Micheline Mattedi Tomazi

Maria da Penha Pereira Lins

CCHN/ PPGEL - Programa de Pós-Graduação em Linguística

Universidade Federal do Espírito Santo

Av. Fernando Ferrari, ${ }^{\circ} 514$

Campus Universitário - Goiabeiras

CEP 29075-910 Vitória - ES

Tel: 0 XX 4009-2801

E-mail: percursoslinguisticos@ hotmail.com

patrickrezende@hotmail.com

guilhermebrambilamanso@ hotmail.com 